\title{
IMPLEMENTAÇÃO DE UM SISTEMA DE INFORMAÇÃO GEOGRÁFICA PARA A GESTÃO DA EMPRESA FLORESTAL
}

\author{
Paulo Costa de Oliveira Filho ${ }^{1}$ \\ Afonso Figueiredo Filho ${ }^{1}$ \\ Flávio Felipe Kirchner ${ }^{2}$ \\ José Simeão de Medeiros ${ }^{3}$ \\ Edilson Batista de Oliveira ${ }^{4}$
}

\begin{abstract}
RESUMO
Este trabalho mostra a integração do modelo administrativo de uma empresa florestal através da implementação de um sistema de informação geográfica. Como base do trabalho, foi utilizado o sistema SPRING (Sistema para Processamento de Informações Georreferenciadas) desenvolvido pelo INPE (Instituto Nacional de Pesquisas Espaciais). Também foram utilizados os sistemas SISPINUS (Simulador de Crescimento e Produção de Pinus elliottii e Pinus taeda) e PLANIN (Planejamento Florestal Integrado), ambos desenvolvidos pela EMBRAPA (Empresa Brasileira de Pesquisa Agropecuária) e UFPR (Universidade Federal do Paraná). O Uso do SPRING integrado a simuladores da produção tornou viável a elaboração de um sistema que possibilita a espacialização da prognose de crescimento e produção por sortimento de madeira bem como da programação de cortes e parâmetros econômicos, até resultados mais avançados de análise espacial. O sistema de informação geográfica implementado apresentou bons resultados e demonstrou grandes possibilidades proporcionando a rápida visualização espacial de informações obtidas como também a integração e produção de novas informações que podem auxiliar os processos de decisão e planejamento das empresas, sobretudo no planejamento e manejo florestal de espécies de rápido crescimento.

Palavras chave: sistemas de informação geográfica, manejo florestal, sistema de simulação do crescimento
\end{abstract}

\section{IMPLEMENTATION OF A GEOGRAPHICAL INFORMATION SYSTEM TO FOREST MANAGEMENT}

\begin{abstract}
This work aimed to show the integration of the administrative model of a forest company through the implementation of a geographical information system. As a base of this work, it was used the system SPRING (System for Processing of Information Georreferenced) developed by INPE (National Institute of Space Researches). Also, the system SISPINUS (Growth and yield Simulator for Pinus elliottii and Pinus taeda) and PLANIN (Integrated Forest Planning), were used both developed by EMBRAPA (Brazilian Company of Agricultural Research) and UFPR (Federal University of Paraná). The use of the SPRING integrated into simulators of the production made viable the construction of a system that make possible the spatialization of the simulated results of forest production, including the spatialization of growth and yield prognosis for wood assortment, as well as of the programming of cuts and economical parameters and advanced results of spatial analysis. The geographical information system implemented presented good results and demonstrated a great contribution providing quick spatial visualization of information of the data base as well as the integration and production of new informations that can aid the decision processes and planning of the companies.

Key-words: geographical information system, forest management, growth simulation system
\end{abstract}

\footnotetext{
${ }^{1}$ Professor e pesquisador da UNICENTRO e do Curso de Pós-Graduação em Engenharia Florestal da UFPR -afig@floresta.ufpr.br

${ }^{2}$ Professor e pesquisador do curso de pós-graduação em engenharia florestal da UFPR - Curitiba-PR.

kirchnner@floresta.ufpr.br

${ }^{3}$ Pesquisador do DPI-INPE - São José dos Campos-SP. simeao@dpi.inpe.br

${ }^{4}$ Pesquisador da EMBRAPA/CNPF - Colombo-PR. ebatista@cnpf.embrapa.br
} 


\section{INTRODUÇÃO}

Atualmente, diante de um novo conceito de trabalho, devido a maior disponibilidade de tecnologias digitais, as empresas cada vez mais repensam seus modelos operacionais e administrativos. Informações valiosas tendem a ser muito mais utilizadas nos processos de decisão e planejamento da empresa, tornando-as cada vez mais independentes e cuidadosas em assegurar mecanismos de sustentabilidade para o futuro. Portanto, a informação, como alternativa para a melhor gestão de negócios, tem sido o caminho para o controle dos recursos naturais e de produção.

Os sistemas de informação geográfica são ferramentas das mais eficientes como integradores de diferentes formatos e tipos de informação, ainda proporcionando um conjunto de operações de análise bastante poderoso. Entre alguns dos sistemas existentes, o SPRING - Sistema de Processamento de Informações Georreferenciadas desenvolvido pelo INPE - Instituto Nacional de Pesquisas Espaciais, tem se destacado como um dos sistemas de informações geográficas mais promissores.

A simulação da produção de plantios florestais tem importância vital para o manejo e o planejamento da empresa florestal. No Brasil, entre os poucos sistemas que fazem a simulação da produção está o SISPINUS Simulador de Crescimento e Produção de Pinus elliottii e Pinus taeda, desenvolvido pela EMBRAPA - Empresa Brasileira de Pesquisa Agropecuária e UFPR - Universidade Federal do Paraná. Este programa possibilita, através da prognose de crescimento e da produção de povoamentos de Pinus, a simulação de desbastes e o sortimento das estimativas de volume total de madeira em volumes parciais, estimados para segmentos dos troncos com dimensões adequadas a cada finalidade industrial. O modelo é baseado em funções de distribuição de probabilidades que descrevem a estrutura diamétrica em classes de sítio e para qualquer idade da floresta, possibilitando ainda a predição da produção em classes de sortimento.

Como ferramenta complementar ao SISPINUS, o programa PLANIN -
Planejamento Florestal Integrado, também desenvolvido pela EMBRAPA e UFPR possibilita os cálculos dos parâmetros econômicos, que viabilizam as análises econômicas de cada simulação de manejo realizada pelo SISPINUS, o que proporciona um suporte valioso para as análises econômico-financeiras dos povoamentos florestais.

\section{OBJETIVOS}

a) Apresentar a estruturação e implementação completa de um sistema de informações geográficas em uma empresa florestal;

b) Apresentar um modelo de uso integrado de dados a partir do SPRING, com o SISPINUS e o PLANIN;

c) Desenvolver e apresentar consultas por expressão lógica, por agrupamentos de atributos do banco de dados e análises espaciais com dados utilizados pelas empresas envolvidas no estudo.

\section{MATERIAIS E MÉTODOS}

\section{Área de Estudo}

A área de estudo utilizada foi uma fazenda situada no município de Sengés, norte pioneiro do Estado do Paraná, e faz parte da fazenda Mocambo, de propriedade da Empresa PISA Florestal S/A. A área pertence aos projetos Mocambo 06 e PISA 33 e está compreendida entre as coordenadas $24^{\circ} 17^{\prime} 42^{\prime}$ '

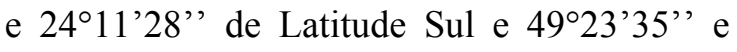
49 $19^{\prime} 40^{\prime \prime}$ de Longitude Oeste (fig. 1). A formação geológica predominante na região é da formação Guaitá ou Itararé com rochas de argilito, folhelhos pirobetuminosos, siltitos calcários e conglomerados. $\mathrm{O}$ relevo predominante na região é suave ondulado, com altitude média de 800 metros, variando de 600 a 1030 metros. O clima dominante na região é do tipo $\mathrm{Cfb}$ - verão quente, com temperatura do mês mais quente abaixo de $22^{\circ} \mathrm{C}$. A vegetação predominante é rasteira característica de cerrado, e grandes áreas de influência antrópica caracterizada por reflorestamentos e agricultura. Os solos predominantes são Latossolo vermelho escuro e câmbico. 


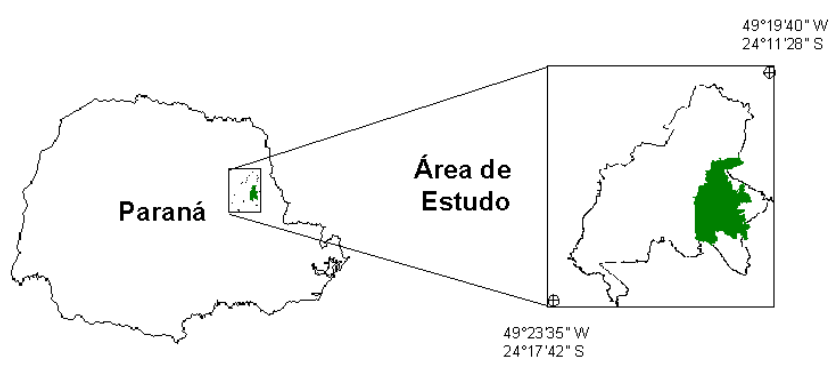

Figura 1: Localização da área de estudo

Figure 1: Localization of the study area

\section{Equipamentos, Softwares e Outros Materiais Utilizados}

Para a realização deste trabalho, foram utilizados os seguintes equipamentos e softwares:

- Microcomputador Pentium III 500 com 128 megabytes de memória ram e 18 gbytes de disco rígido;

- - SPRING (INPE) versões 3.4, 3.5 Beta e os módulos SCARTA e IPLOT;

- Sistema Gerenciador de Banco de Dados Access;

- Sistema SISPINUS (EMBRAPA/CNPF e UFPR);

- Sistema PLANIN (EMBRAPA/CNPF e UFPR).

Foi utilizado também o seguinte material complementar :

- - Mapa digital da área de estudo, obtido junto à empresa PISA Florestal S/A;

- Cadastro básico de informações e de inventário florestal realizado em 1997, identificando os talhões de reflorestamento da PISA Florestal S/A pertencentes à área de estudo;

- Informações sobre custos de implantação e manutenção dos povoamentos da área de estudo da PISA Florestal S/A.

\section{Procedimentos Metodológicos}

A empresa possui um sistema de manutenção e atualização tanto da base cartográfica quanto de cadastro. Foram utilizados os sistemas SISPINUS e PLANIN, integrando simulações de produção florestal e análise econômica ao banco geográfico implementado, para permitir a espacialização destas simulações, através de agrupamentos, consultas, e finalmente análises espaciais. Para dar início aos trabalhos de implementação do SIG na área da empresa, foram obtidos dados tanto cartográficos (em formato digital) quanto de cadastro, custos de implementação e manutenção e de inventário florestal. Todos os procedimentos utilizados podem ser visualizados no organograma da figura 2 .

\section{Construção do Modelo de Dados}

Dentro do esquema conceitual do SIG, foram utilizados vários tipos de informação em formatos digitais distintos e feita a caracterização ou classificação dos dados de entrada em seu modelo correto ou operacional, de acordo com a tabela 1.

$\mathrm{Na}$ seqüência, foi feita a transferência de dados vetoriais do CAD para o SIG, no formato .dxf, nível por nível, sendo que, não foi verificado qualquer problema de conversão de toda a base cartográfica original no formato .cad (maxicad) para o formato .dxf.

Tabela 1: Modelo de dados

Table 1: Types of data

\begin{tabular}{l|l|l}
\hline \multicolumn{1}{c|}{ CATEGORIA } & \multicolumn{1}{c}{ MODELO } & PLANOS DE INFORMAÇÃO \\
\hline Imagem & Campo Tipo Imagem & Mosaico_Rec \\
\hline Mapa_Talhões & Mapa Tipo Cadastral & $\begin{array}{l}\text { Limite_Fazenda } \\
\text { Limite_Talhões }\end{array}$ \\
\hline Altimetria & Campo Tipo MNT & Curvas_Rec \\
\hline Hidrografia & Campo Tipo Temático & Rios \\
\hline Rede_Viária & Mapa Tipo Rede & Estradas_Principais \\
\hline Talhões & Objeto Tipo Espacial & \\
\hline
\end{tabular}




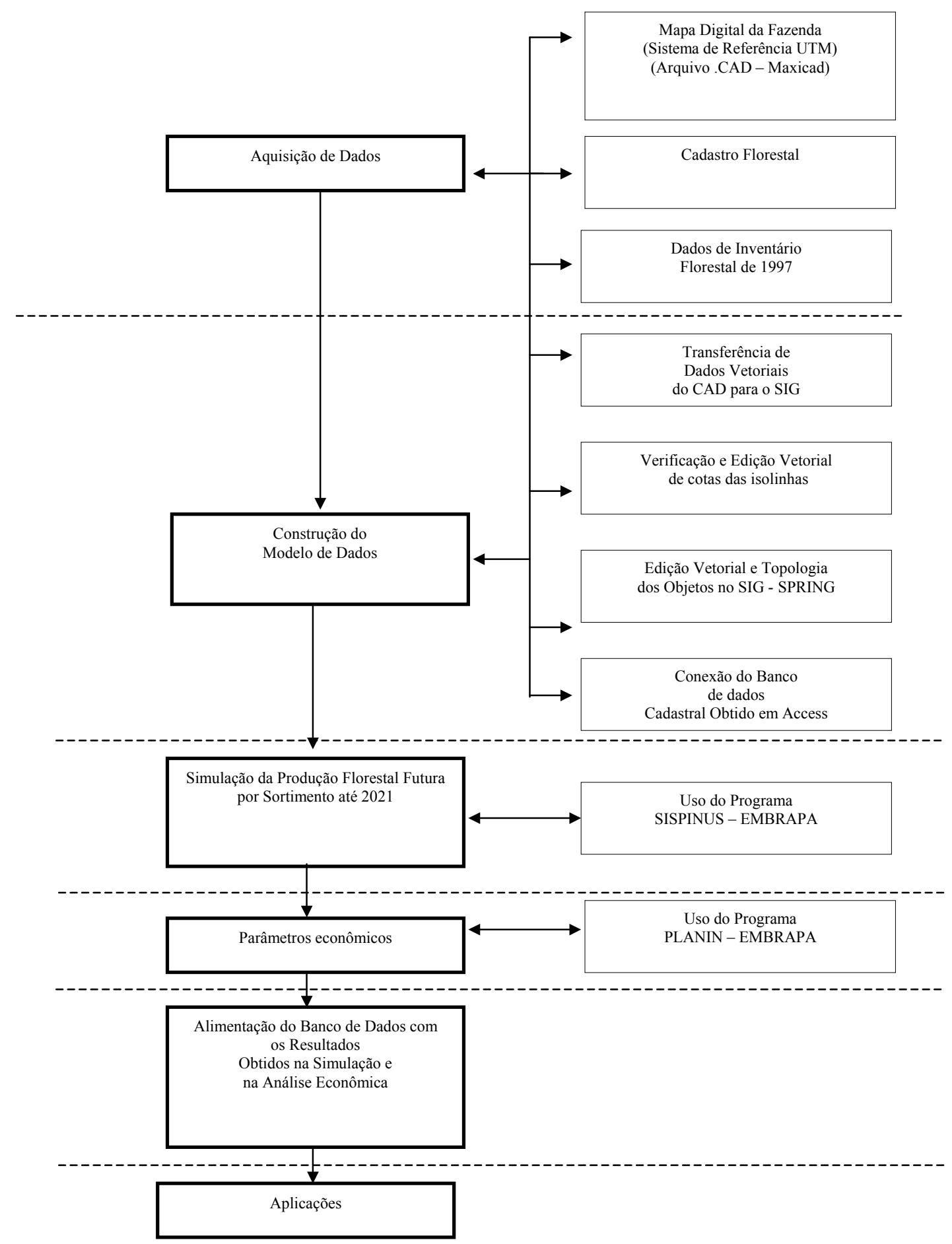

Figura 2: Representação da sequência operacional do trabalho para a construção do modelo de dados Figure 2: Representation of the operational sequence to the construction of the database model 
Foram importados para o SIG os níveis de informação: estradas principais, hidrografia, limite da fazenda, limite dos talhões, curvas de nível (isolinhas), além das fotografias utilizadas na confecção de um mosaico não controlado, que foi registrado com a base cartográfica da fazenda.

A etapa seguinte foi a edição vetorial e finalmente a geração dos polígonos. Iniciou-se pela transformação e incorporação de arquivos vetoriais do CAD para o SIG, passando a seguir à edição e finalmente à poligonalização dos objetos, que neste caso foram definidos como sendo os talhões florestais. Foi feita a edição vetorial necessária: fechamento de polígonos, formação de nós, para finalmente transformar os polígonos-talhões em geoobjetos ajustados e poligonalizados. Também as isolinhas ou curvas de nível exigiram um trabalho de edição tanto de cotas quanto ajustes de linhas.

A partir dos dados de inventário florestal realizado em 1997, o programa SISPINUS possibilitou, através da prognose de crescimento e da produção de povoamentos de Pinus, a simulação de desbastes e a separação das estimativas de volumes parciais, estimados para segmentos dos troncos com as dimensões adequadas a cada finalidade industrial da empresa. Isto é possível porque o programa SISPINUS apresenta um modelo baseado em funções de distribuição de probabilidades que descrevem as distribuições de diâmetro e altura das árvores do povoamento em diversas idades, sítios e prediz a produção e seu sortimento. Também a partir de dados do mesmo inventário florestal, além de informações de custos de implantação e atividades operacionais cedidas pela PISA Florestal S/A, o programa PLANIN possibilitou o cálculo dos parâmetros de avaliação econômica dos regimes de manejo simulados para os povoamentos.

Este modelo de dados foi criado com o objetivo principal de fornecer subsídios espaciais ao planejamento da produção e manejo florestal dos povoamentos do gênero Pinus spp. Desta forma, foi possível obter mapas que indicassem um cenário da produção por sortimento de madeira, obtidos a partir da simulação da produção futura com base em dados de inventário florestal realizado no passado.

Além disso, várias informações não espaciais (atributos) obtidas no cadastro da empresa em questão, foram associadas aos geo-objetos pré-definidos, ou seja, aos talhões de reflorestamento de Pinus spp, e espacializadas na forma de mapas. $\mathrm{O}$ sistema proporcionou a visualização de atributos do banco de dados tanto por agrupamento quanto por consulta. Foram gerados mapas das mais variadas informações, visualizadas nos fluxogramas das figuras 3 e 4 .

A partir das curvas de nível num intervalo de 10 em 10 metros, foi gerado o modelo digital do terreno (grade regular) através da qual foi feito o mapa hipsométrico da fazenda em classes de 20 em 20 metros e de 50 em 50 metros.

A partir das isolinhas de nível, foi feita a grade triangular (TIN - Triangular Irregular Network), através da qual foi gerada a grade regular de declividade porcentual. $\mathrm{Na}$ seqüência, fez-se uma classificação, criando-se um plano de informação temático com 5 (cinco) classes de declividade.

Diversas operações de análise espacial foram executadas, utilizando-se da Linguagem espacial para Geoprocessamento Algébrico (LEGAL) do programa SPRING, na intenção de combinar os dados simulados de produção com outras informações de interesse. Para a utilização das ferramentas de análise espacial, alguns dos planos de informação foram espacializados, gerando-se as suas respectivas grades regulares ou modelos numéricos. A figura 5 ilustra outras aplicações que utilizaram operações de programação em LEGAL, bem como ferramentas de análise espacial. Maiores detalhes sobre as operações de análise espacial utilizadas podem ser vistos em Medeiros (1999), ou ainda em Assad e Sano (1998).

O recurso da consulta espacial através de expressões lógicas é bastante importante quando for necessário obter a rápida seleção e visualização de objetos (em tempo real) que envolvem uma série de atributos, operações e valores. 


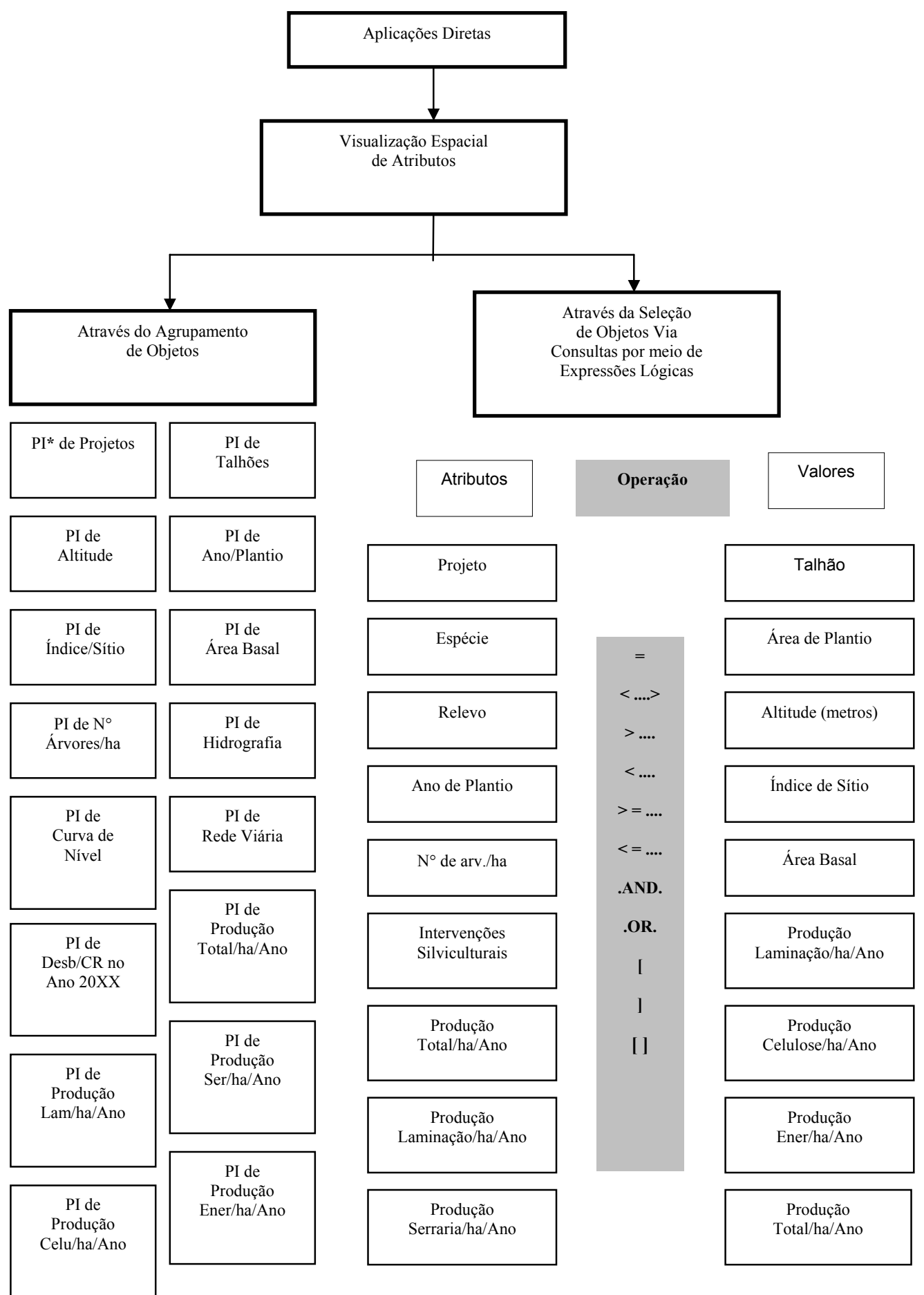

Obs.: * PI = Plano de Informação

Figura 3: Representação das diferentes aplicações diretas obtidas no modelo de dados formado Figure 3: Representation of the diferents aplications from the database model 
Implementação de um sistema de informação...

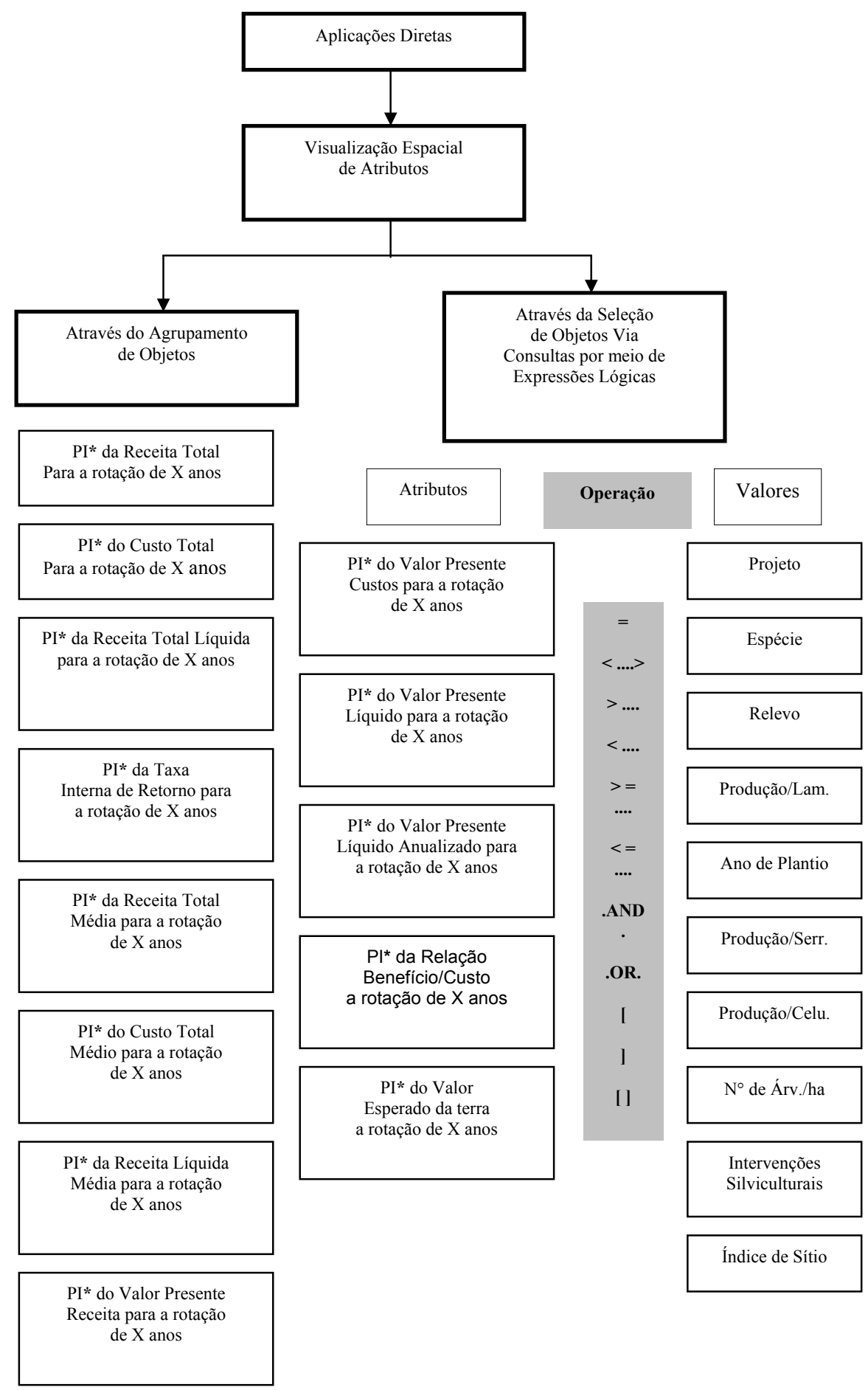

Figura 4: Representação das diferentes aplicações diretas obtidas no modelo de dados com utilização de parâmetros econômicos

Figure 4: Representation of the differents aplications from the database model with use of economic parameters 

foram construídas:

Como exemplo, as seguintes expressões, aplicadas ao planejamento florestal da empresa

a) Expressão Lógica da Consulta 01:

(Comentários)

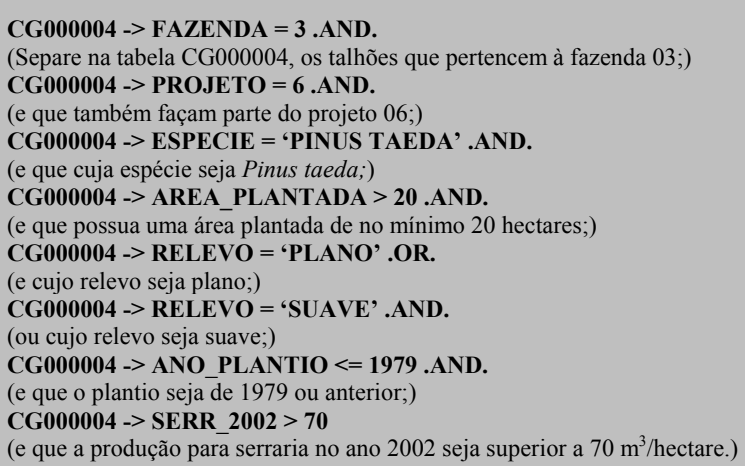

\section{b) Expressão Lógica da Consulta 02:}

\section{(Comentários)}

Desb->ANO_2013 = 'CR22' .AND.

(Separe na tabela Desb, os talhões que tenham previsão de corte raso para o ano 2013;)

CG000004->LAM 2013 > $=160$.AND.

(e separe na tabela $\bar{C}$ G000004, aqueles talhões que também tenham uma produção

para laminação no ano 2013 igual ou superior a $160 \mathrm{~m}^{3} / \mathrm{ha}$;)

CG000004->RELEVO >= 'PLANO' .AND.

(e cujo relevo seja plano;

CG000004->ESPECIE $>=$ 'PINUS TAEDA'

(e cuja espécie seja Pinus taeda.)

\section{c) Expressão Lógica da Consulta 03:}

(Comentários)

CG000004->ESPECIE $=$ 'PINUS TAEDA' .AND.

(Separe na tabela CG000004, os talhões cuja espécie seja Pinus taeda;)

R22->VAL_PRES_LIQ_NA > 50

(e separe na tabela $\bar{R} 22$, aqueles talhões que também apresentem o parâmetro de

avaliação econômica Valor Líquido Presente Anualizado igual ou superior a R\$ 50,00/ha)

Em função da grande importância em se relacionar produção com sítio, foram espacializados, como exemplo, os seguintes planos de informação:

1) Produção para o sortimento laminação no ano $2014\left(\mathrm{~m}^{3} / \mathrm{ha}\right)$

2) Índice de sítio (m).

Os programas foram desenvolvidos para a espacialização ou formação do modelo numérico representativo dos dois planos de informação. Após a espacialização de ambos os planos de informação, foram definidas algumas operações para a combinação dos planos espacializados.

Os programas foram desenvolvidos, para a análise espacial e formação do modelo temático representativo do resultado. 
Implementação de um sistema de informação...

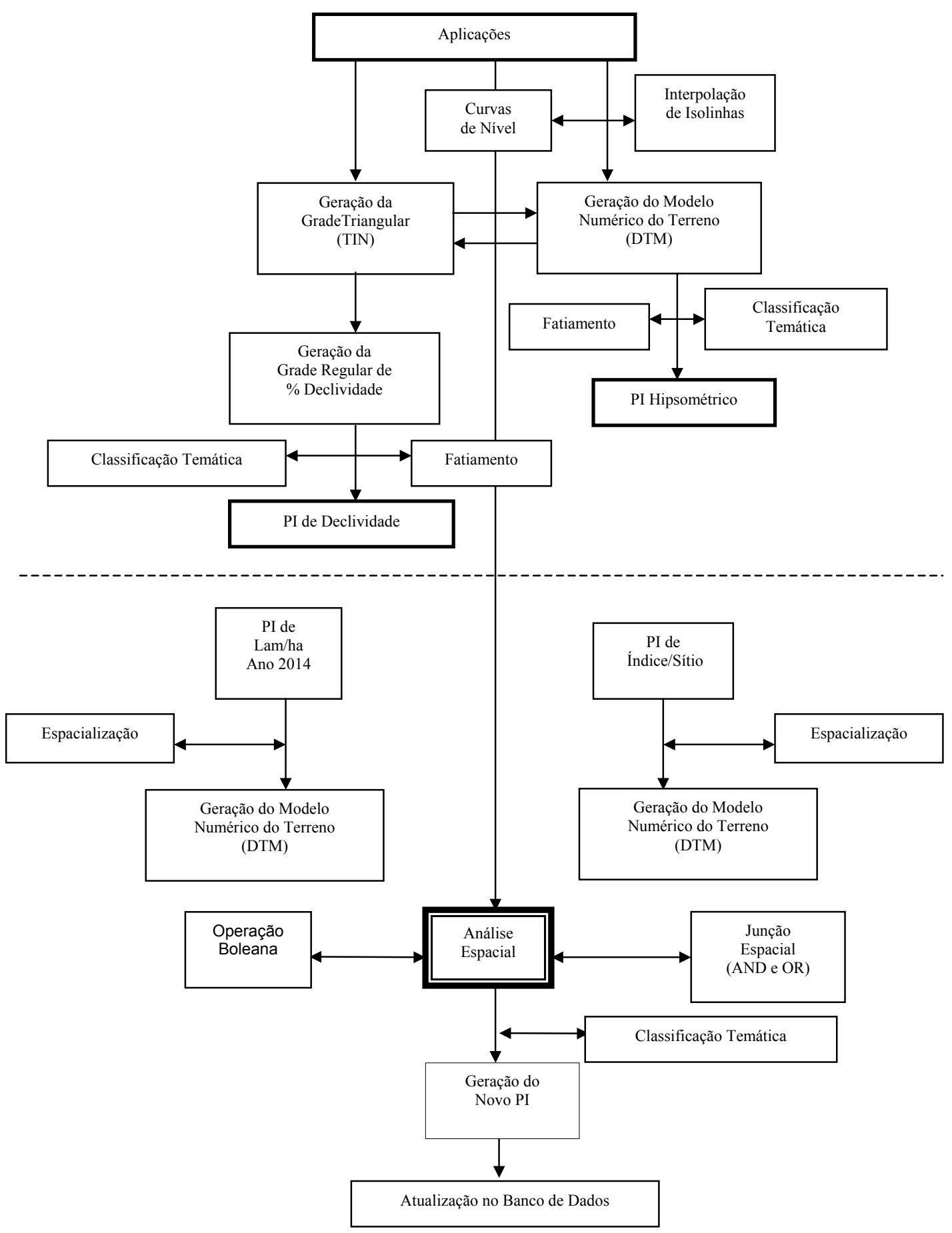

Figura 5: Representação das diferentes aplicações obtidas com uso da linguagem espaço geográfica e técnicas de análise espacial

Figure 5: Representation of the diferent aplications obtained with the use of the spacial geographical language and spacial analist techniques 
a) Programa para a Espacialização da Produção para o Sortimento Laminação no ano 2014 $\left(\mathrm{m}^{3} / \mathrm{ha}\right)$

\{

//CONVERSAO DE OBJETOS (CADASTRAL) EM NUMERICO

//GERACAO DE UM MNT A PARTIR DE ATRIBUTO NUMERICO

//DA TABELA DE OBJETOS

//DECLARACOES

Objeto objTAL ("Talhoes");

Cadastral mapcad ("Mapa_Talhoes");

Digital SaiMNT ("MNT");

//RECUPERA O PI CADASTRAL

mapcad = Recupere (Nome $=$ "Talhoes");

//CRIA PI MNT

SaiMNT $=$ Novo $($ Nome $=$ "LAM 2014", $\operatorname{ResX}=10, \operatorname{ResY}=10$, Escala $=20000, \operatorname{Min}=0.0000$, Max $=300.0)$;

// EXECUTA A OPERACAO

SaiMNT = Espacialize (objTAL."Lam_2014" OnMap mapcad);

\}

\section{b) Programa para a Espacialização do Índice de Sítio}

//CONVERSAO DE OBJETOS (CADASTRAL) EM NUMERICO

//GERACAO DE UM MNT A PARTIR DE ATRIBUTO NUMERICO

//DA TABELA DE OBJETOS

//DECLARACOES

Objeto objTAL ("Talhoes");

Cadastral mapcad ("Mapa_Talhoes");

Digital SaiMNT ("MNT");

//RECUPERA O PI CADASTRAL

mapcad $=$ Recupere $($ Nome $=$ "Talhoes");

//CRIA PI MNT

SaiMNT $=$ Novo $($ Nome $=$ "INDICE DE SITIO", $\operatorname{Res} X=10, \operatorname{Res} Y=10$, Escala $=20000$, Min= 0.0000, Max $=100.0)$

// EXECUTA A OPERACAO

SaiMNT = Espacialize (objTAL."ÍNDICE_DE_SÍTIO" OnMap mapcad);

\}

c) Programa para a combinação do Índice de Sítio com a Produção do sortimento Laminação do ano 2014 através da operação Boleana

//SOBREPOSICAO DO INDICE DE SITIO COM LAMINACAO 2014

//ATRAVES DE OPERACAO BOLEANA COM OPERADOR AND.

Tematico indsit ("IndSit_tem");

Tematico produc ("Producao_Lam");

Tematico saida ("Overlay")

indsit = Recupere (Nome= "IS");

produc $=$ Recupere $($ Nome $=$ "lam_2014");

saida $=$ Novo $($ Nome $=$ "ISxlam2014", $\operatorname{Res} X=10, \operatorname{Res} Y=10$, Escala=20000)

// EXECUCAO DA OPERACAO DE SOBREPOSICAO

saida $=$ Atribua (CategoriaFim $=$ "Overlay")

\{

"Alto-Alta" : (indsit.Classe == "Alto" .AND. produc.Classe == "Alta"),

"Alto-Moderada" : (indsit.Classe == "Alto" .AND. produc.Classe == "Moderada"),

"Alto-Media" : (indsit.Classe == "Alto" .AND. produc.Classe == "Media"),

"Alto-Baixa" : (indsit.Classe == "Alto" .AND. produc.Classe =="Baixa"),

"Alto-MuitoBaixa" : (indsit.Classe == "Alto" .AND. produc.Classe == "MuitoBaixa"),

"Moderado-Alta" : (indsit.Classe == "Moderado" .AND. produc.Classe == "Alta"),

"Moderado-Moderada" : (indsit.Classe == "Moderado" .AND. produc.Classe == "Moderada"),

"Moderado-Media" : (indsit.Classe == "Moderado" .AND. produc.Classe == "Media"),

"Moderado-Baixa" : (indsit.Classe == "Moderado" .AND. produc.Classe == "Baixa"),

"Moderado-MuitoBaixa" : (indsit.Classe == "Moderado" .AND. produc.Classe == "MuitoBaixa"),

"Medio-Alta" : (indsit.Classe == "Medio" .AND. produc.Classe == "Alta"),

"Medio-Moderada" : (indsit.Classe == "Medio" .AND. produc.Classe == "Moderada"),

"Medio-Media" : (indsit.Classe == "Medio" .AND. produc.Classe == "Media"),

"Medio-Baixa" : (indsit.Classe == "Medio" .AND. produc.Classe == "Baixa"),

"Medio-MuitoBaixa" : (indsit.Classe == "Medio" .AND. produc.Classe == "MuitoBaixa"),

"Baixo-Alta" : (indsit.Classe == "Baixo" .AND. produc.Classe == "Alta"),

"Baixo-Moderada" : (indsit.Classe == "Baixo" .AND. produc.Classe == "Moderada"),

"Baixo-Media" : (indsit.Classe == "Baixo" .AND. produc.Classe $==$ "Media"),

"Baixo-Baixa" : (indsit.Classe == "Baixo" .AND. produc.Classe == "Baixa"),

"Baixo-MuitoBaixa" : (indsit.Classe == "Baixo" .AND. produc.Classe == "MuitoBaixa"),

"MuitoBaixo-Alta" : (indsit.Classe == "MuitoBaixo" .AND. produc.Classe == "Alta"),

"MuitoBaixo-Moderada" : (indsit.Classe == "MuitoBaixo" .AND. produc.Classe == "Moderada"),

"MuitoBaixo-Media" : (indsit.Classe == "MuitoBaixo" .AND. produc.Classe == "Media"),

"MuitoBaixo-Baixa" : (indsit.Classe == "MuitoBaixo" .AND. produc.Classe == "Baixa"),

"MuitoBaixo-MuitoBaixa" : (indsit.Classe == "MuitoBaixo" .AND. produc.Classe == "MuitoBaixa")

\} 


\section{d) Programa para a combinação do Índice de Sítio com a Produção do sortimento Laminação do ano 2014 através da Junção Espacial (.AND)}

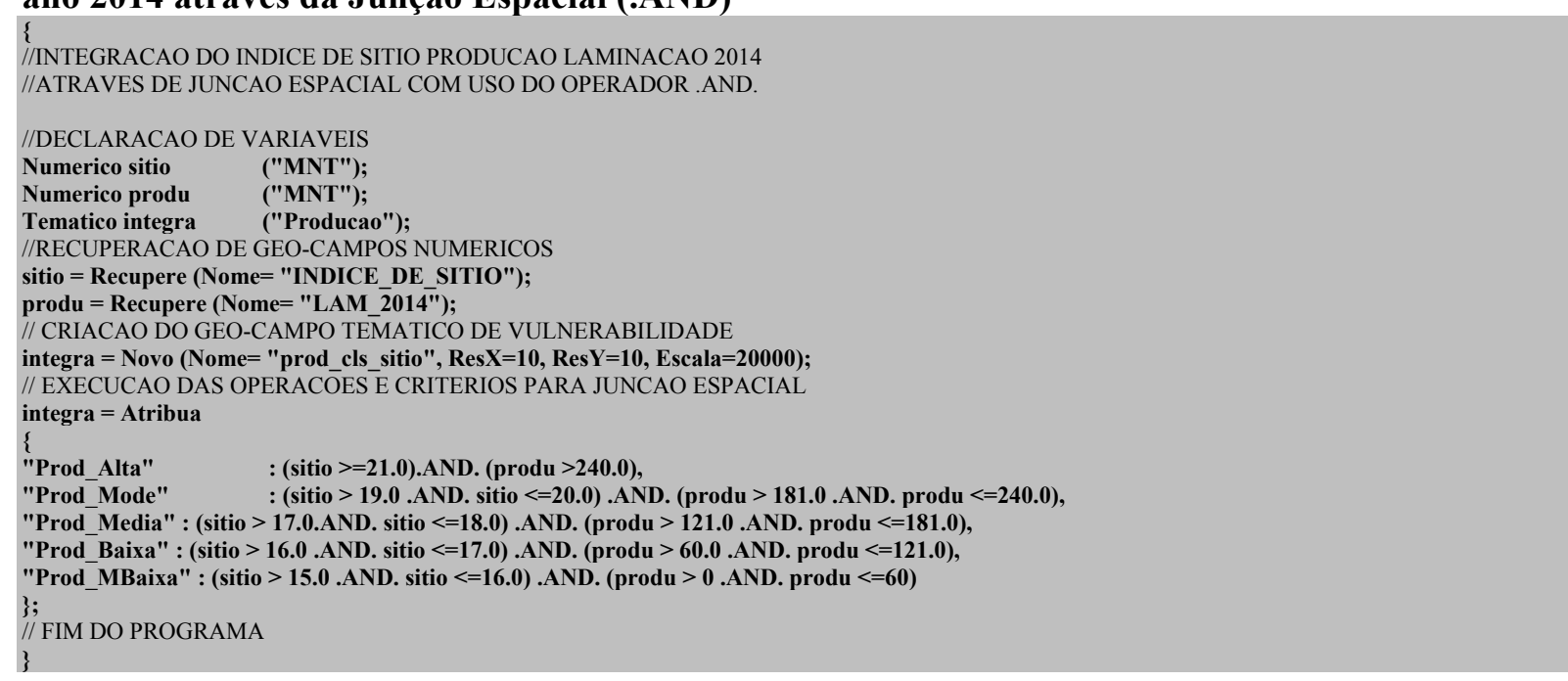

e) Programa para a combinação do Índice de Sítio com a Produção do sortimento Laminação do ano 2014 através da Junção Espacial (.AND e .OR.)

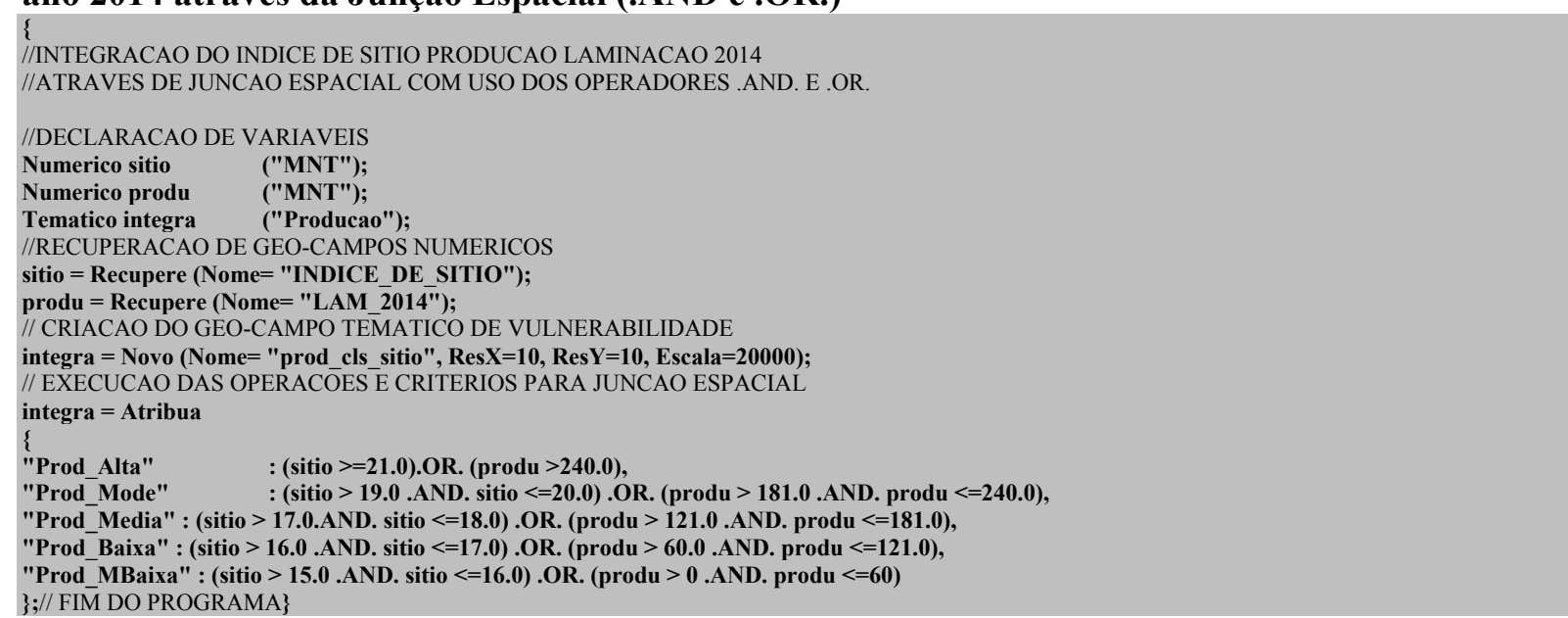

\section{RESULTADOS E DISCUSSÃO}

Partindo-se de uma base cartográfica ajustada, bem como um cadastro atualizado, trabalhou-se diretamente na construção do modelo de dados do SIG e na simulação de produção por sortimento de matéria-prima a partir dos dados de inventário florestal realizado no ano de 1997. Além disso, foi feito o cálculo dos parâmetros de avaliação econômica dos povoamentos considerando rotações econômicas desde os 22 anos até os 30 anos, a partir de dados de custos de implantação dos povoamentos obtidos junto à empresa.

A partir dos dados simulados tanto de produção quanto econômicos, foi possível construir um cenário que permite uma melhor visualização de detalhes inerentes a todo o processo produtivo da empresa que está associado aos geo-objetos pré-determinados, ou seja, os talhões florestais que são as unidades de manejo.

De posse dos dados obtidos no inventário florestal e do regime de manejo fictício, procedeu-se as simulações de produção por sortimento desde 1997 até o ano de 2021. Foi considerado o seguinte regime de manejo ainda bastante tradicional e muito utilizado no sul do país: desbastes aos 08, 12 e 16 anos e o corte final aos 22 anos. Considerando que mudanças devido à questão econômica e mercado, são normais e comuns à política das empresas, foram feitas as simulações de produção para cada talhão, até a idade de 30 
anos. Foram obtidos valores simulados de produção em $\mathrm{m}^{3} /$ hectare para quatro sortimentos de mercado utilizados pela empresa: Produção para laminação, serraria, celulose e energia . Para mostrar que o potencial de trabalho do sistema de informações ultrapassa os limites das questões estritamente técnicas e atinge também o campo econômico, foi feito o cálculo de parâmetros importantes para a análise econômica dos povoamentos da área de estudo com base nos custos de implementação e manutenção bem como preços de madeira cedidos pela PISA Florestal S/A, utilizando-se o sistema PLANIN.

A utilização do sistema PLANIN, assim como o sistema SISPINUS ou outros simuladores, mostra-se inteiramente adequada tendo seus resultados integrados ao sistema de informações. Desta forma, muitas empresas do ramo, que já utilizam estes sistemas ou outros similares, podem integrar seus resultados ao SIG sem que haja uma necessidade condicional de programar estas simulações dentro do sistema. Maiores vantagens são observadas utilizando-se das ferramentas do SIG como agrupamento, consulta ou análise destes dados com outros dados espaciais e não espaciais, no intuito de produzir novas informações, bem como visualizá-las espacialmente.

Inicialmente, tendo o banco de dados alfanumérico associado à base cartográfica da fazenda, foram obtidos vários planos de informação que originaram mapas temáticos gerados a partir da espacialização de atributos do banco de dados por agrupamento de objetos, e trabalhados nos módulos independentes SCARTA/IPLOT, utilizados na confecção dos mapas e impressão. Uma das mais recentes atualizações do sistema SPRING se refere exatamente à capacidade de gerar planos de informação a partir das tabelas resultantes de consultas e agrupamentos. Este avanço coloca o SPRING efetivamente no mercado profissional dos sistemas de informações geográficas, pois permite que qualquer atributo do banco de dados bem como análises produzidas sejam armazenadas como planos de informação contendo informações temáticas ou numéricas.

Foram obtidos os seguintes mapas temáticos, dos quais, alguns foram colocados como anexos neste trabalho, enquanto os demais podem ser vistos em Oliveira Filho (2001):
- Mapa de talhões da fazenda (anexo 1)

- Mapa de altitudes médias

- Mapa de índice de sítio

- Mapa do número de árvores por hectare

- Mapa de curvas de nível

- Mapa hipsométrico de 50 em 50 metros

- Mapa de uso do solo

- Mapas do programa de corte para 1998 (anexo

5)

- Mapa do programa de corte para 2000

- Mapa do programa de corte para 2003

- Mapa do programa de corte para 2007

- Mapa do programa de corte para 2013

- Mapa de produção para laminação por hectare no ano (anexo 3)

- Mapa de produção para celulose por hectare no ano 2012

- Mapa da receita total na rotação de 22 anos

- Mapa do custo total médio na rotação de 22 anos

- Mapa do valor presente receita na rotação de 22 anos

- Mapa do valor presente líquido na rotação de 22 anos

- Mapa de relação benefício/custo na rotação de 22 anos

- Mapa da taxa interna de retorno para a rotação de 22 anos (anexo 8)

- Mapa de projetos

- Mapa de ano de plantio

- Mapa de área basal média

- Mapa de rede viária e hidrografia

- Mapa hipsométrico de 20 em 20 m (anexo 2)

- Mapa de declividades

- Mapa do programa de corte para 1997

- Mapa do programa de corte para 1999

- Mapa do programa de corte para 2002

- Mapa do programa de corte para 2006

- Mapa do programa de corte para 2012 (anexo

6)

- Mapa de produção total por hectare em 2012

- Mapa de produção para serraria por hectare no ano 2012 (anexo 4)

- Mapa de produção para energia por hectare no ano simulado

- Mapa do custo total na rotação de 22 anos

- Mapa da receita líquida média na rotação de 22 anos

- Mapa de valor presente dos custos na rotação de 22 anos

- Mapa do valor presente líquido anualizado na rotação de 22 anos (anexo 7)

- Mapa do valor esperado da terra na rotação de 22 anos 
A próxima etapa do trabalho foi a visualização de atributos do banco de dados através da seleção de objetos via consultas por meio de expressões lógicas. Neste caso, a rápida seleção de objetos com uso de expressões matemáticas, mostrou bastante operacionalidade em tempo real considerando a importância para a empresa, dos atributos envolvendo o manejo florestal e econômico utilizados nas consultas.

As ferramentas de análise espacial utilizadas na combinação dos planos de informação Produção de Laminação $\left(\mathrm{m}^{3} / \mathrm{ha}\right)$ no ano 2014 com o plano de informação Índice de Sítio, mostraram-se eficientes, sendo observadas as vantagens no uso da junção espacial em relação à operação boleana de overlay devido principalmente à maior liberdade de atribuição de critérios para a determinação dos intervalos de classe. Como resultados destas análises, foram produzidos os seguintes planos de informação:

- Mapa da reclassificação do índice de sítio após a espacialização ou geração do modelo numérico

- Mapa resultante da operação de junção espacial entre o índice de sítio e a produção para o sortimento laminação no ano 2014

- Mapa da reclassificação da produção para o sortimento laminação no ano 2014 após a espacialização

\section{CONCLUSÕES}

Conforme os objetivos propostos no presente trabalho, e após uma análise dos resultados obtidos, conclui-se que:

- O sistema SPRING apresenta características em seu modelo de dados que permitem manipular diversos tipos de informações de forma bastante educativa e prática, além de ser ao mesmo tempo um programa profissional;

- A integração do sistema SPRING com os sistemas SISPINUS e PLANIN mostrou-se bastante promissora, na medida em que os dados simulados por estes dois sistemas são facilmente integrados ao banco de dados utilizado pelo SPRING;

- Muitas outras informações poderão ser obtidas na forma espacial na medida em que haja uma combinação de informações através de outras ferramentas de análise do SIG;
- A integração do sistema SPRING com os sistemas SISPINUS e PLANIN foi possível, no estudo de caso 2, após a edição e formatação dos resultados simulados por estes sistemas. Recomenda-se que, à medida que estes programas tenham suas versões atualizadas para o ambiente windows, esta integração e alimentação de dados possa ser automatizada na sua disposição funcional dos dados.

\section{REFERÊNCIAS}

ALMEIDA, M. S.; FEIGUEIRAS, C. A.; SHIMABUQURO, Y. E. Sistema de informação geográfica aplicado ao manejo de florestas implantadas. In: Geoprocessamento São Paulo: Escola Politécnica da Universidade de São Paulo. 1990. p. 262-265.

ALVES, D. S. Sistemas de informação geográfica. In: Geoprocessamento. São Paulo: Escola Politécnica da Universidade de São Paulo. 1990. p. 66-78.

ASSAD, E. D.; SANO, E. E. Sistema de informações geográficas: aplicações na agricultura. Planaltina: EMBRAPA-CPAC. 1998. $274 \mathrm{p}$.

BIERWAGEN, R.; ONUKI, M.; BERGAMASCHI, R. Integração SIG-SAS cadastro florestal para implantação de um sistema de informações florestais. In: SEMINÁRIO DE ATUALIZAÇÃO EM SENSORIAMENTO REMOTO E SISTEMAS DE INFORMAÇÕES GEOGRÁFICAS APLICADOS À ENGENHARIA FLORESTAL. 4. 2000. Curitiba: Anais... Attilio A. Disperati. p. 69-77.

BRINKER, R. W.; JACKSON, B. D. Using a geographic information system to study a Regional wood procurement problem. Forest Science. Lawrence. US: v. 37, n. 6, p. 16141631. 1991.

BURROUGH, P. A. Principles of geographic information systems for land resources assessment. Oxford: Claredon Press. 1989. $200 \mathrm{p}$.

CÂMARA, G. et. al Anatomia de sistemas de informação geográfica. Campinas: Instituto de Computação-Unicamp. 1996. 
COUTO, H. T. Z. Sistemas de informações geográficas: aplicações florestais. Piracicaba: IPEF. 1993. 18 p. (Série Técnica).

HOFER, R. M. Basic concepts of geographic information systems and remote sensing for forest resource management. In: ENCONTRO BRASILEIRO DE ECONOMIA E PLANEJAMENTO FLORESTAL, 2., 1991, Curitiba: Anais... EMBRAPA. 1991. p. 305331.

MAcLEAN, H. E. Smart maps: forestry's newest frontier. American Forests. Washington, DC: v. 101, n. 3/4, p. 13-20, Mar./April. 1995.

MEDEIROS, J. S. Utilização de sistema de informações geográficas como ferramenta auxiliar no gerenciamento florestal. In: SEMINÁRIO DE ATUALIZAÇÃO EM SENSORIAMENTO REMOTO E SISTEMAS DE INFORMAÇÕES GEOGRÁFICAS APLICADOS À ENGENHARIA FLORESTAL. 1. 1994. Curitiba: Anais...: FUPEF. 1994. p. 93-101.
MEDEIROS, J. S. Bancos de dados geográficos e redes neurais artificiais: tecnologias de apoio à gestão do território. São Paulo: 1999. Tese (Doutorado em Geografia Física) - Departamento de Geografia, Faculdade de Filosofia, Letras e Ciências Humanas, Universidade de São Paulo.

OLIVEIRA-FILHO, P. C. Implementação de sistemas de informação geográfica para a gestão da empresa florestal. Curitiba: 2001: Tese (Doutorado em Engenharia Florestal) Setor de Ciências Agrárias, Universidade Federal do Paraná.

OLIVEIRA, E. B. Um sistema computadorizado de prognose do crescimento e produção de Pinus taeda L., com critérios quantitativos para a avaliação técnica e econômica de regimes de manejo. Curitiba: 1995. Tese (Doutorado em Engenharia Florestal) - Setor de Ciências Agrárias, Universidade Federal do Paraná. 
Implementação de um sistema de informação...

ANEXOS

MAPA DOS TALHÕES DA FAZENDA (anexo 1)

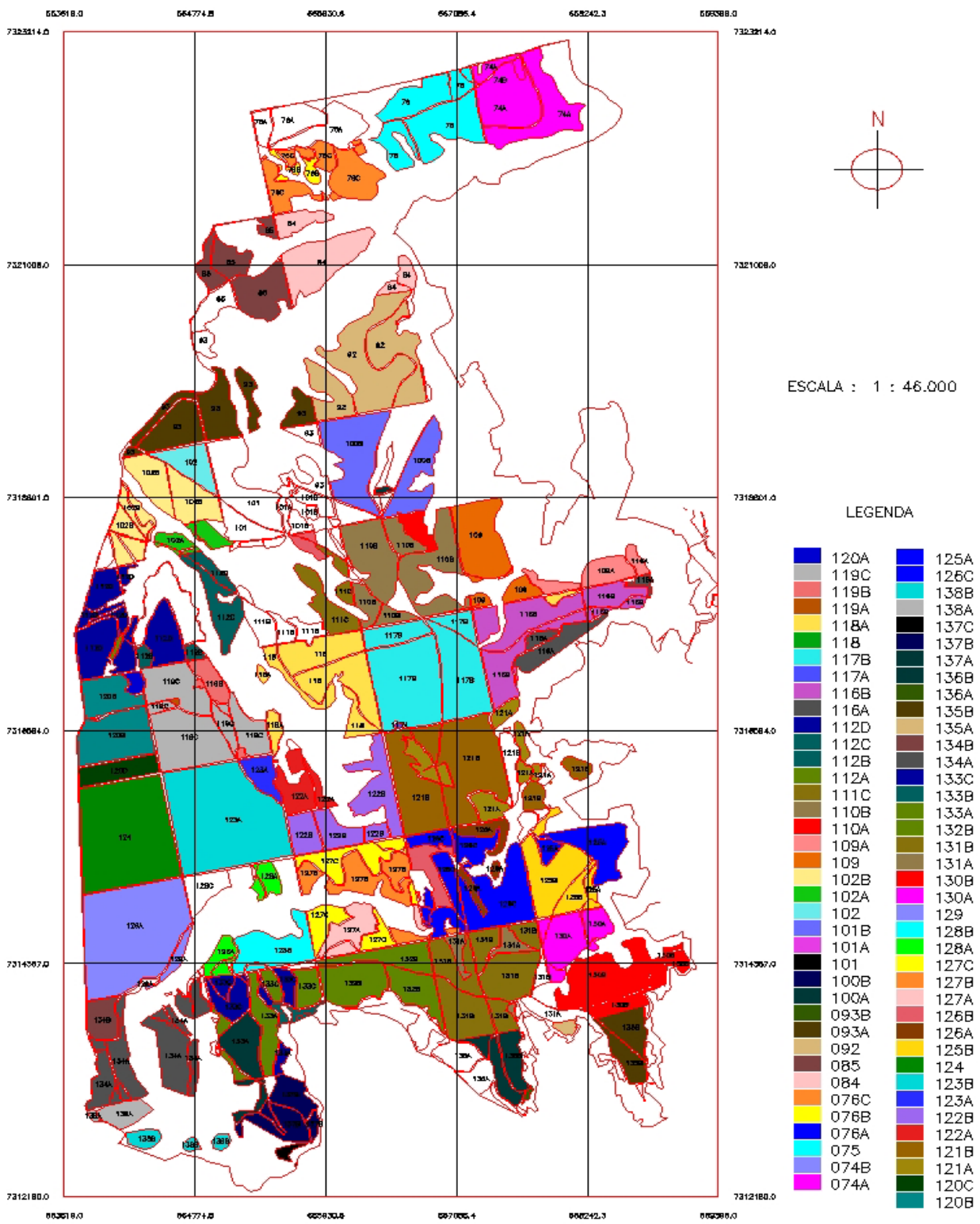


Oliveira Filho, P. C. de; et al

MAPA HIPSOMÉTRICO DE 20 EM 20 m (anexo 2)

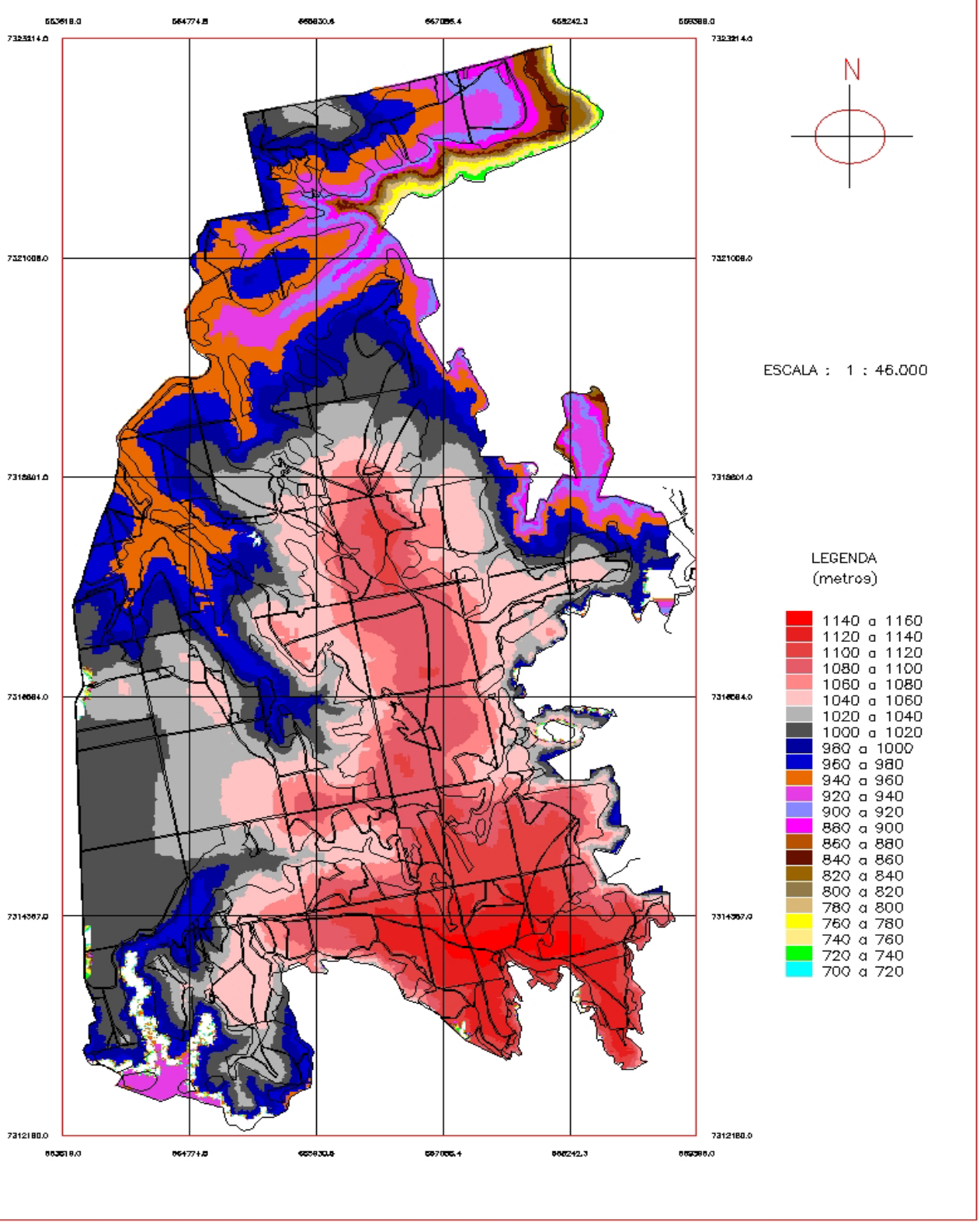


Implementação de um sistema de informação...

MAPA DE PRODUÇÃO PARA LAMINAÇÃO POR HECTARE ANO 2012 (anexo 3)

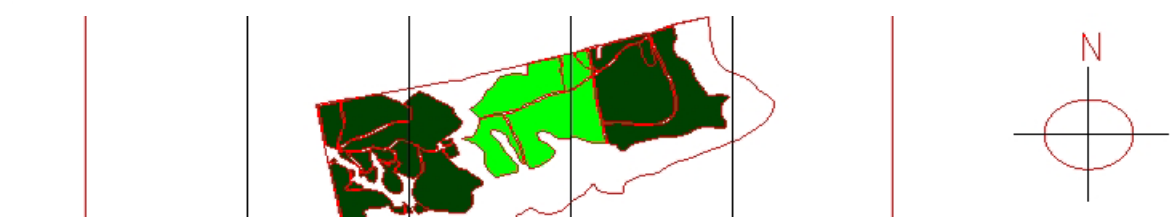

ESCALA : $1: 46.000$

$\mathrm{m3} /$ hectare)

$>229.80$ a 236.00

164.10 a 210.80

$>140.800164 .10$

$>140.80 a 164.10$
131.50 a 140.80
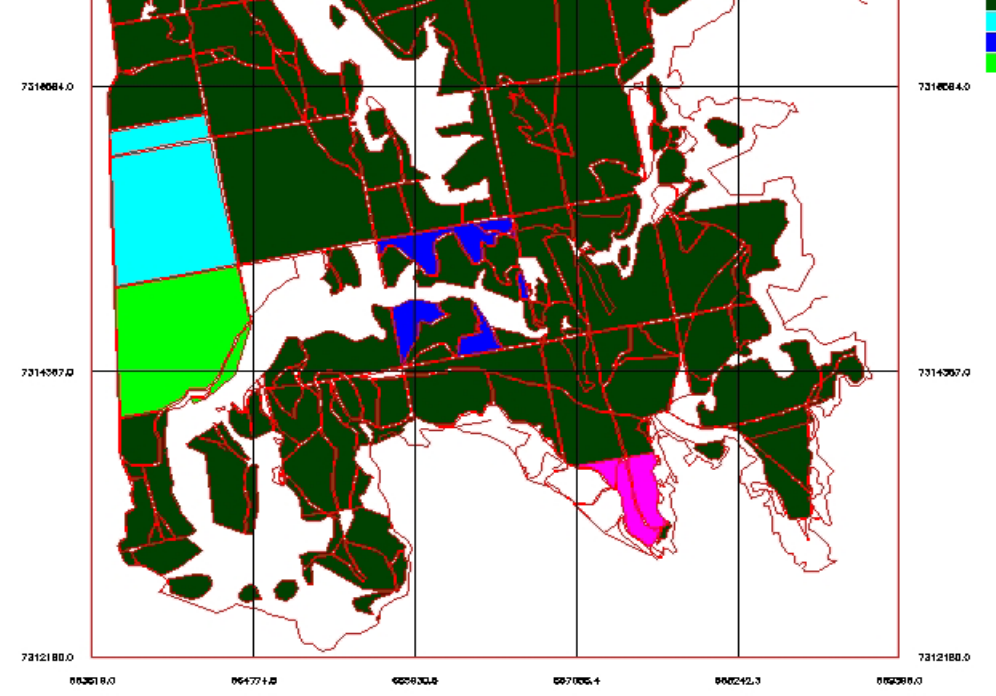
MAPA DE PRODUÇÃO PARA SERRARIA POR HECTARE NO ANO 2012 (anexo 4)

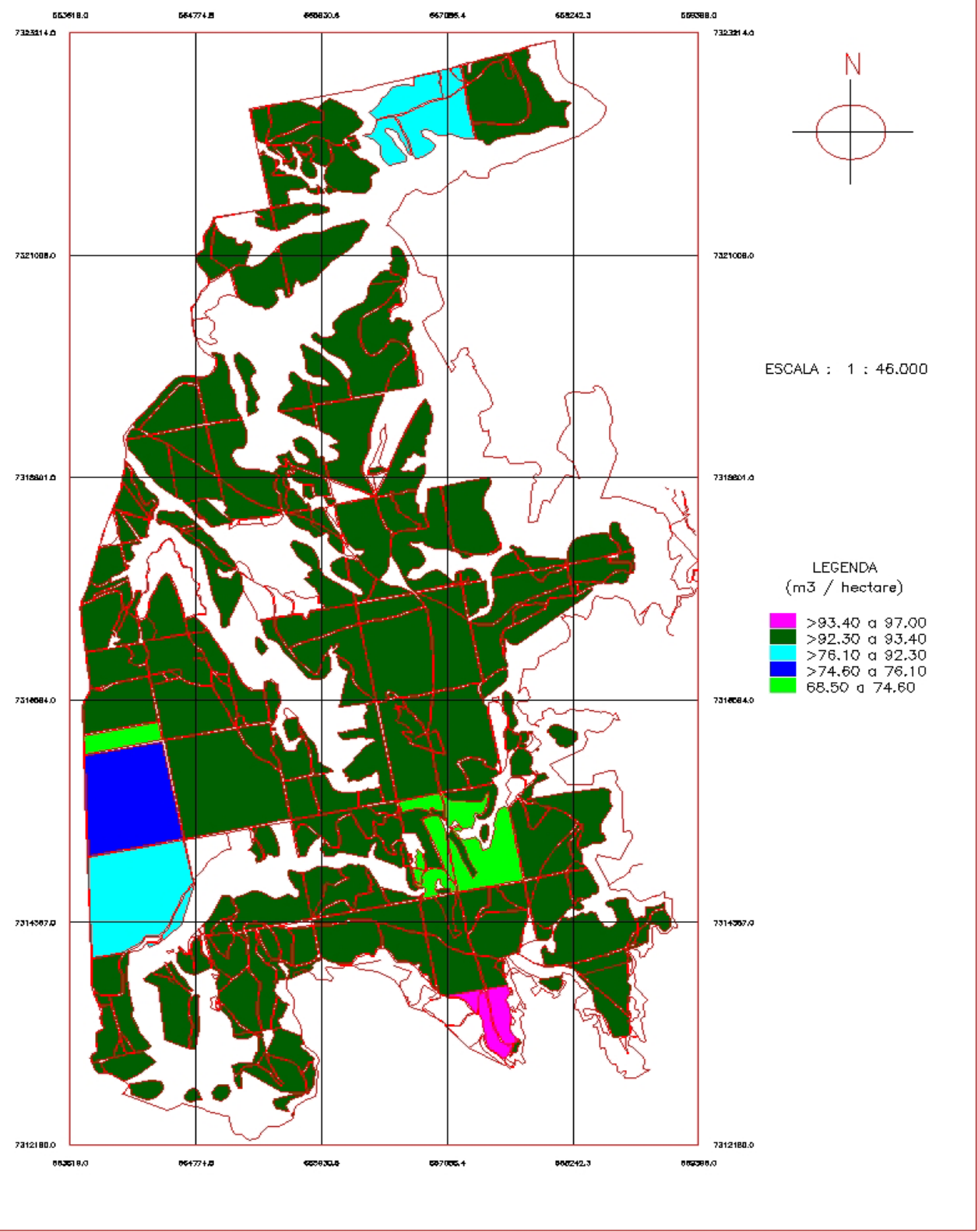


Implementação de um sistema de informação...

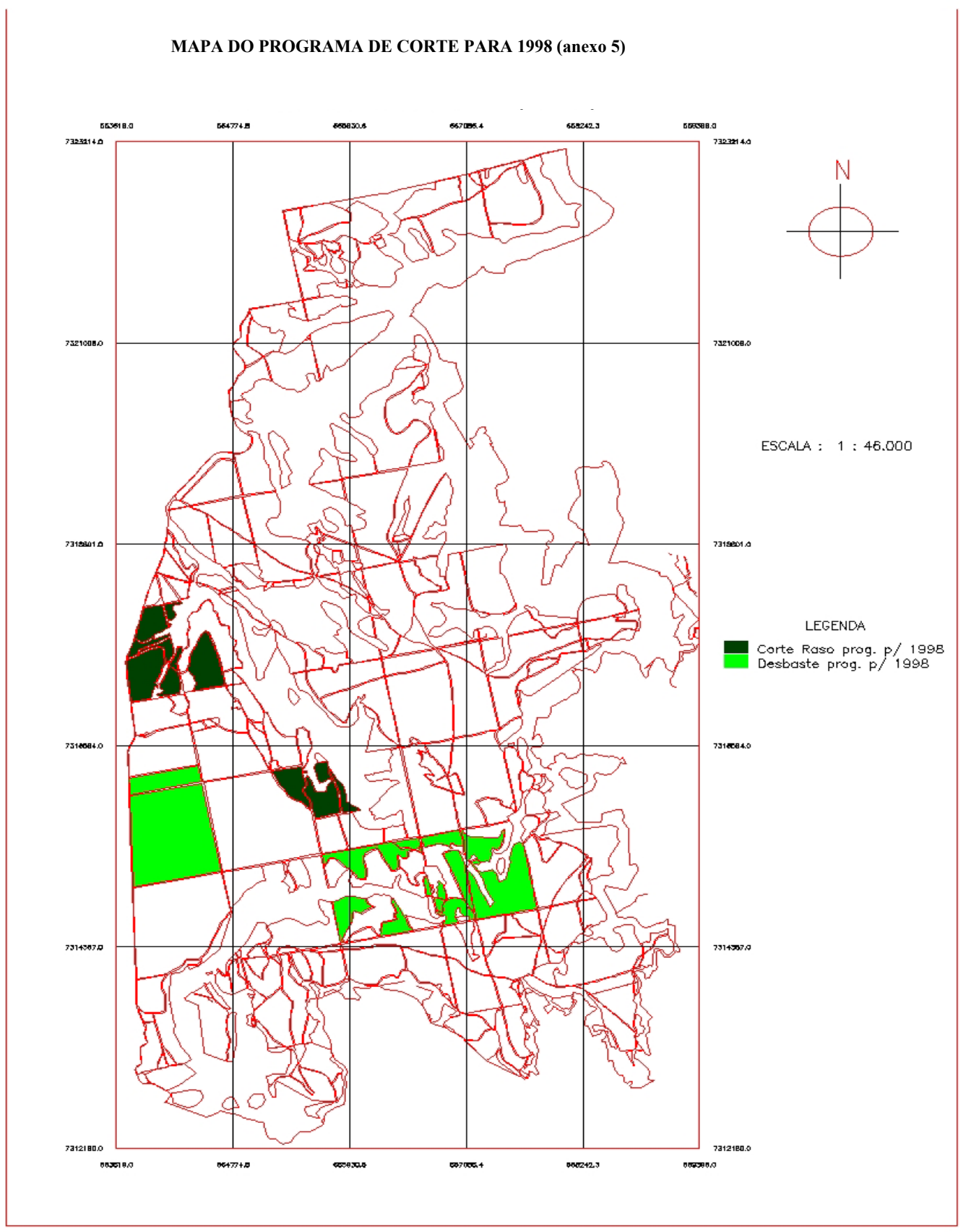




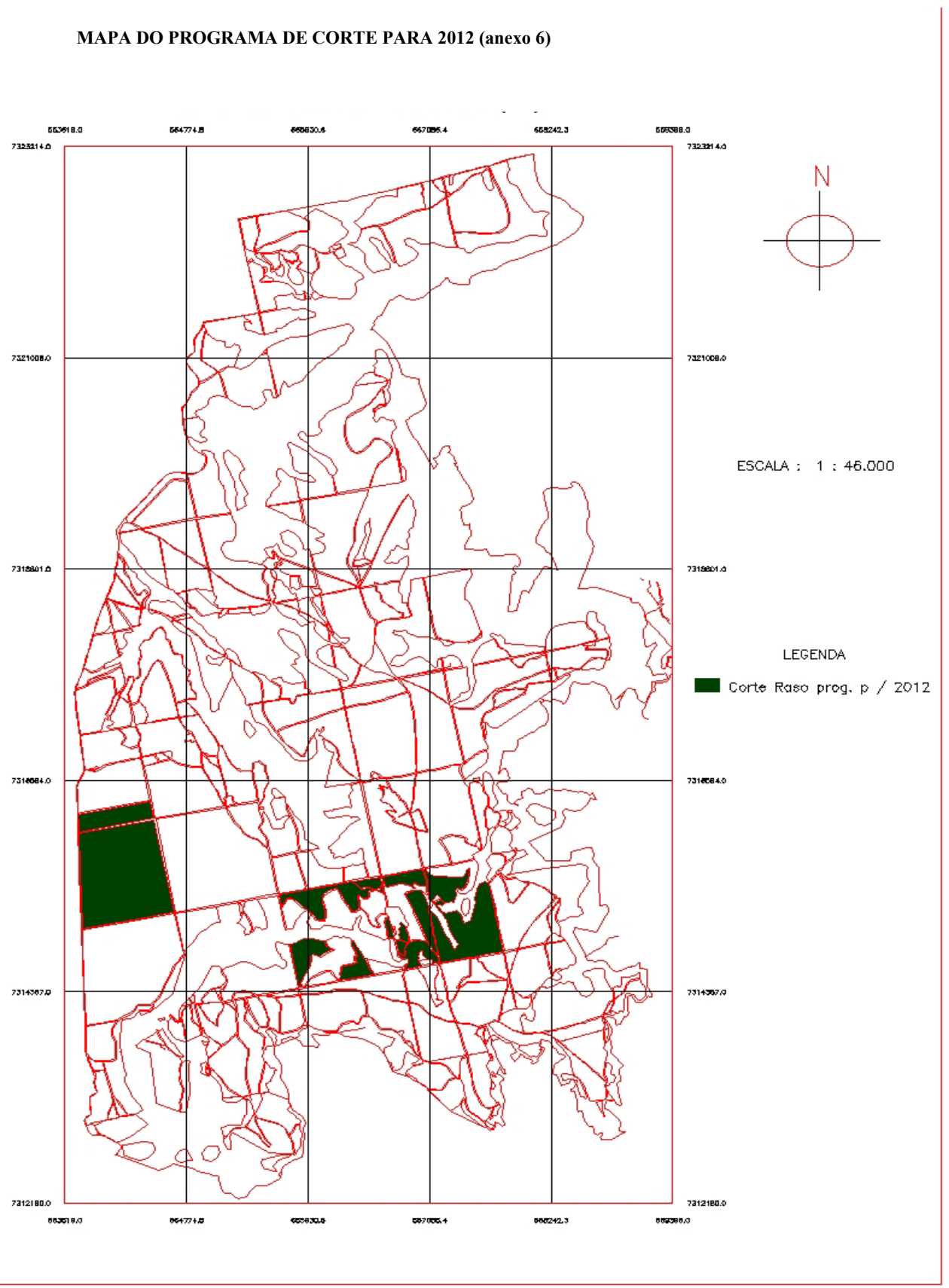


Implementação de um sistema de informação...

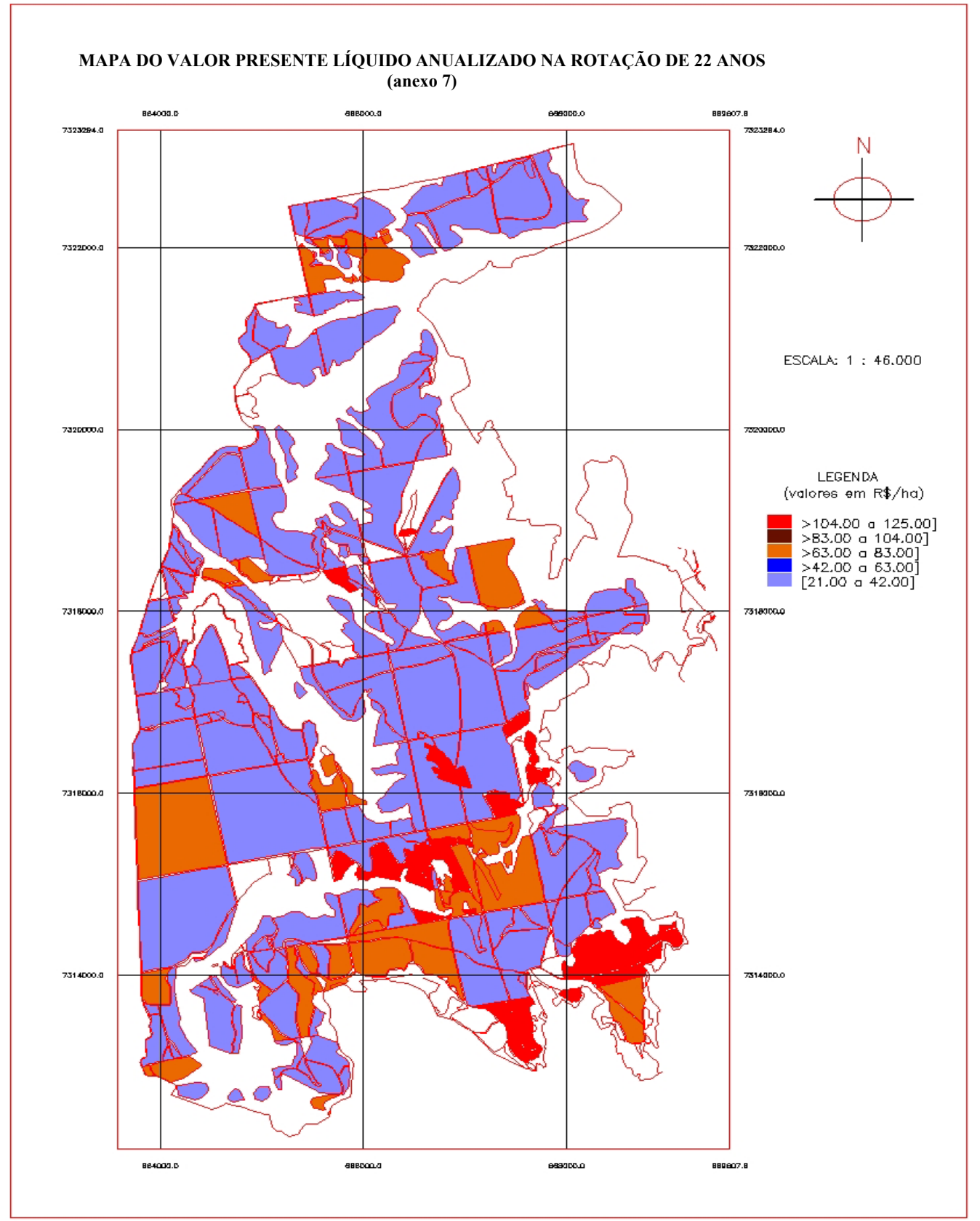




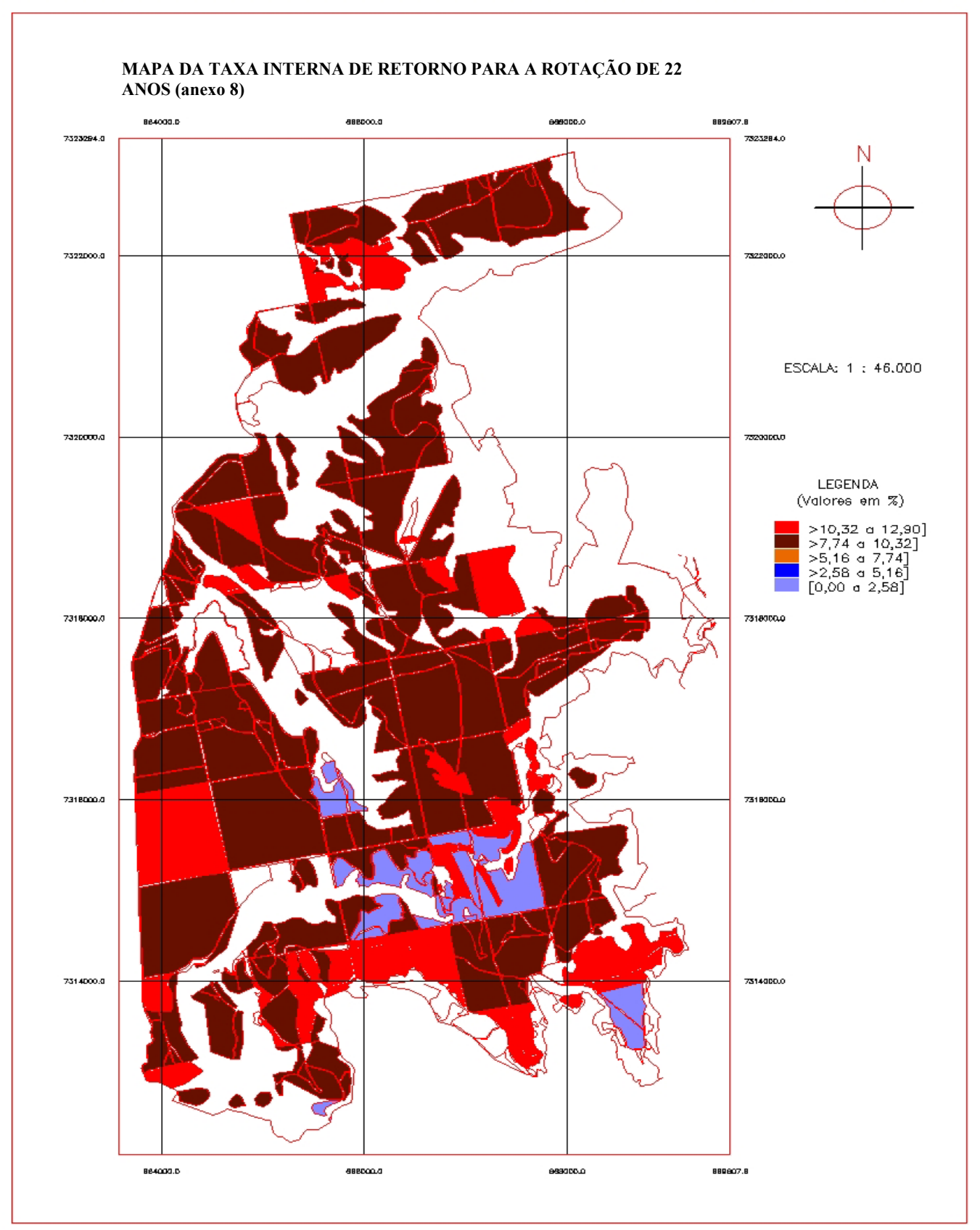

